\title{
The circadian clock modulates anti-cancer properties of curcumin
}

\author{
Ashapurna Sarma ${ }^{1}$, Vishal P. Sharma ${ }^{1,2}$, Arindam B. Sarkar $^{3}$, M. Chandra Sekar ${ }^{3}$, Karunakar Samuel ${ }^{1}$ \\ and Michael E. Geusz ${ }^{1 *}$
}

\begin{abstract}
Background: Curcuminoids of the spice turmeric and their enhanced derivatives have much potential as cancer treatments. They act on a wide variety of biological pathways, including those regulating cell division and circadian rhythms. It is known that circadian clocks can modify cancer therapy effectiveness, according to studies aimed at optimizing treatments based on the circadian cycle. It is therefore important to determine whether treatments with curcumin or similar chemotherapeutic agents are regulated by circadian timing. Similarly, it is important to characterize any effects of curcumin on timing abilities of the circadian clocks within cancer cells.

Methods: We examined the circadian clock's impact on the timing of cell death and cell division in curcumintreated C6 rat glioma cells through continuous video microscopy for several days. To evaluate its persistence and distribution in cancer cells, curcumin was localized within cell compartments by imaging its autofluorescence. Finally, HPLC and spectroscopy were used to determine the relative stabilities of the curcumin congeners demethoxycurcumin and bisdemethoxycurcumin that are present in turmeric.
\end{abstract}

Results: Circadian rhythms in cell death were observed in response to low $(5 \mu \mathrm{M})$ curcumin, reaching a peak several hours before the peak in rhythmic expression of mPER2 protein, a major circadian clock component. These results revealed a sensitive phase of the circadian cycle that could be effectively targeted in patient therapies based on curcumin or its analogs. Curcumin fluorescence was observed in cell compartments at least $24 \mathrm{~h}$ after treatment, and the two congeners displayed greater stability than curcumin in cell culture medium.

Conclusions: We propose a mechanism whereby curcuminoids act in a sustained manner, over several days, despite their tendency to degrade rapidly in blood and other aqueous media. During cancer therapy, curcumin or its analogs should be delivered to tumor cells at the optimal phase for highest efficacy after identifying the circadian phase of the cancer cells. We confirmed the greater stability of the curcumin congeners, suggesting that they may produce sustained toxicity in cancer cells and should be considered for use in patient care.

Keywords: Circadian rhythm, Glioma, Curcumin, Curcuminoids, Chronopharmacology, Apoptosis, Cell cycle

\section{Background}

Curcumin is a promising phytochemical for treating several cancers. This ingredient of the spice turmeric has been used to treat several ailments for thousands of years because of its anti-inflammatory, anti-microbial, and wound-healing properties [1]. Curcumin's anticancer properties have much potential when used alone or in combination with standard chemotherapies or

\footnotetext{
* Correspondence: mgeusz@bgsu.edu

'Department of Biological Sciences, Bowling Green State University, 217 Life

Science Building, Bowling Green, OH 43403, USA

Full list of author information is available at the end of the article
}

radiation treatments. It arrests tumor cell proliferation by inhibiting multiple signal transduction pathways, interfering with the cell cycle, and inducing apoptosis. Relative to most agents currently used to target cancer cells, curcumin is reported to have low toxicity towards normal cells $[2,3]$. The molecular targets of curcumin and related curcuminoids include several transcription factors, oncogenes, and signaling proteins engaged in cancer initiation and progression $[4,5]$. For example, NF-kB (nuclear factor-kB) and AP-1 (activator protein1) are constitutively active in cancer cells, and curcumin enhances apoptosis by blocking signaling pathways that 
rely on these transcription factors $[2,6]$. Curcumin has multiple molecular targets through which it causes cell toxicity in various types of cancers, including gliomas [5, 7-16]. Additionally, curcumin used in combination with cisplatin or doxorubicin, common chemotherapy drugs, induces apoptosis in glioblastoma cell lines [15].

One weakness of curcumin as a cancer treatment is its poor bioavailability and rapid degradation in the body. Nevertheless, the two major congeners in the turmeric root, demethoxycurcumin (DMC) and bisdemethoxycurcumin (BDMC) may persist longer in tissues than curcumin. DMC, BDMC, and the major curcumin metabolite tetrahydrocurcumin could provide a sustained anticancer effect [17-19].

Another temporal factor influencing the efficacy of cancer therapies is the circadian rhythm that is prominent in many physiological processes $[20,21]$. The circadian timing system generates approximately 24-h rhythms in the body through autonomous intracellular circadian clocks, including ones identified in many cancer cells $[22,23]$. The role of these clocks in cancer is not yet known, although circadian-regulated proteins appear to alter tumor growth rate [24-27]. As the molecular mechanism of circadian clocks is explored in greater depth, chemotherapy regimens based on circadian rhythms are being developed and tested [28].

The molecular circadian timing within clock cells could be altered by curcumin treatments. One likely curcumin target, Bmal1, is a critical gene within the molecular oscillator producing circadian rhythms. Bmal1 is activated by curcumin through stimulation of PPAR- $\gamma[29,30]$. Studies also suggest that polyphenols such as curcumin activate sirtuin 1 (SIRT1), which also regulates circadian rhythms. SIRT1, a histone deacetylase, indirectly controls the circadian clock by (1) down-regulating NF-kB [31]; (2) inhibiting nuclear localization of the clock protein mPER2 through deacetylation of the tumor suppressor PML [32]; and (3) binding to the CLOCK-BMAL1 dimer, promoting deacetylation and degradation of mPER2 [33]. Thus, curcumin could alter circadian rhythms in normal and cancer cells, although there are no reported effects on the circadian timing mechanism.

Drug chronotherapy (use of circadian timing to optimize pharmacokinetics or pharmacodynamics) is an effective medical approach [34]. Many proteins involved in drug absorption, metabolism or elimination display daily oscillations in synthesis or activity. Studies with rodents show differing effects and toxicities from chemotherapeutic drugs depending on time of day of administration [35]. Reported circadian regulation of chemotherapeutic treatments includes anticancer drugs 5-flurouracil, doxorubicin, roscovitine, and platinum complex analogs cisplatin, carboplatin, and oxaliplatin [36-38]. Some but not all of these effects likely depend on the ability of circadian clocks to regulate daily cell division timing. The most effective time of day when chemotherapies based on curcumin should be administered to patients is unknown. In this study, we identified a phase of the circadian cycle when a low dose of curcuminoids is most effective at inducing death of rat glioma cancer cells in vitro, and we found that circadian rhythms in gene expression persist at this dosage.

\section{Methods \\ Cell culture}

Rat C6 glioma cells were cultured in Dulbecco's Modified Eagle Medium (DMEM) containing penicillin (100 units/ $\mathrm{ml})$, streptomycin $(100 \mu \mathrm{g} / \mathrm{ml}), 10 \%$ fetal bovine serum (FBS), and no pyruvate or phenol red (complete medium). Cells were grown in 100-mm tissue culture dishes at $37{ }^{\circ} \mathrm{C}$ in $5 \% \mathrm{CO}_{2}$ and were passaged when they were nearly confluent. Cells were cotransfected with a construct producing a fusion protein of MPER2 and firefly luciferase (mPer2::mPer2:luc) along with $C M V:: n e o$ [39]. These bioluminescent reporter gene cells were used in most experiments.

\section{Bioluminescence assay}

C6 cells containing the mPer2::mPer2:luc reporter gene were seeded $\left(10^{5}\right.$ cells/dish $)$ in $35-\mathrm{mm}$ tissue culture dishes and incubated in DMEM medium containing $10 \% \mathrm{FBS}$ at $37{ }^{\circ} \mathrm{C}$ in $5 \% \mathrm{CO}_{2}$. When the plates were 90-100\% confluent, the cells were washed twice with a $10 \mathrm{mM}$ HEPES-buffered, low-bicarbonate (4.2 mM), phenol red-free DMEM, designed for use in room air, combined with $10 \% \mathrm{FBS}$, which was designated as final medium (FM), After an exchange with FM, cells were treated with $20 \mu \mathrm{M}$ forskolin in ethanol $(0.01 \% \mathrm{v} / \mathrm{v})$ for $2 \mathrm{~h}$ to synchronize the cellular circadian clocks. Immediately before imaging, $0.2 \mathrm{mM}$ of the luciferase substrate luciferin (Xenogen) was added. For experiments with lowdose curcumin, $0.2 \mathrm{mM}$ luciferin and $5 \mu \mathrm{M}$ curcumin (CUR, Sigma-Aldrich C-1386) were added to the plate $12 \mathrm{~h}$ after forskolin treatment. To monitor rhythmic expression of the clock protein, bioluminescence was recorded using a Wallac Victor 1420 Multilabel plate reader (Perkin Elmer). Culture dishes were maintained at $37{ }^{\circ} \mathrm{C}$ while readings were taken hourly for 50 to $96 \mathrm{~h}$. The background noise was subtracted from each reading and signals were summed across replicate cultures.

\section{Curcumin treatment}

To examine circadian rhythms in cell division and cell death after treatment with different doses of CUR, C6 cells were seeded at a density of $6 \times 10^{5}$ cells in $60-\mathrm{mm}$ dishes containing complete medium and then grown overnight to $50 \%$ confluency. They were then given one of three treatments: $20 \mu \mathrm{M}$ forskolin for $2 \mathrm{~h}$, forskolin 
for $2 \mathrm{~h}$ followed by $5 \mu \mathrm{M}$ CUR, or forskolin followed by $10 \mu \mathrm{M}$ CUR, all in FM. For forskolin treatments, cells were washed twice with FM, medium was exchanged with the forskolin treatment, and then cells were incubated for $2 \mathrm{~h}$ at $37{ }^{\circ} \mathrm{C}$. CUR was dissolved in dimethyl sulfoxide (DMSO) to make a $25 \mathrm{mM}$ stock solution and was diluted in FM before the treatment.

\section{Long-term time-lapse cell imaging}

To image individual mitotic and apoptotic events a single field of view of cells maintained in FM and sealed in a $60-\mathrm{mm}$ dish was captured at 5-min intervals using time-lapse videography continuously over 4-6 days. The imaging system consisted of an inverted microscope with a 20x objective lens, red LED light source, and a digital color camera. The imaging system was placed inside a $37{ }^{\circ} \mathrm{C}$ incubator to maintain ideal culture conditions. Time-lapse recording software FLIX (Nimisis.com) captured live cell events, and each image from the time series was analyzed by eye and with Image software (National Institutes of Health).

\section{Immunocytochemistry}

Immunofluorescence staining was used to identify apoptotic cells and verify the peak and trough of the circadian rhythm in apoptotic events. C6 cells were fixed in $100 \%$ methanol for $5 \mathrm{~min}$ and standard immunocytochemistry methods were used to identify cleaved caspase-3-positive cells. Anti-cleaved caspase-3 primary antibody (Cell Signaling) was used at 1:1000 dilution. The samples were rinsed after overnight incubation at $4{ }^{\circ} \mathrm{C}$, and were then incubated for $2 \mathrm{~h}$ with Alexa488-conjugated, complementary secondary antibody. For nuclear staining, cells were stained with Hoechst 33342 (10-20 ng/ml, Invitrogen) for 2 min. Cells were imaged with a DMI3000B inverted fluorescence microscope (Leica Microsystems), a Rolera Thunder cooled-CCD camera with a back-thinned, backilluminated, electron-multiplying sensor (Photometrics), $\mathrm{X}$-Light spinning-disk confocal unit (CrestOptics), and a Spectra X LED light engine (Lumencore) with image acquisition and processing controlled by Metamorph software (Molecular Devices). Images were collected with a 40x objective lens along with standard DAPI and fluorescein filters. Images were further analyzed with ImageJ software.

\section{Curcumin localization in $\mathrm{C} 6$ cells}

For autofluorescence imaging of curcumin, C6 cells were grown in 35-mm glass-bottom dishes (MatTek) for one day, treated with $5 \mu \mathrm{M}$ CUR in DMSO, and incubated at $37^{\circ} \mathrm{C}$. After $1 \mathrm{~h}$ or $24 \mathrm{~h}$, cells were washed with FM and autofluorescence was imaged using standard fluorescein filters. Images were captured with the confocal fluorescence imaging system and a $63 x$ oil immersion lens. After
$24 \mathrm{~h}$, additional treated cells were fixed with methanol, stained with Hoechst, and imaged using DAPI filters.

\section{Spectral analysis of curcumin}

The absorption spectrum of $5 \mu \mathrm{M}$ CUR in final medium with DMSO was measured with a GENESYS 10S UV-vis Spectrophotometer. In a second set of measurements, cells in 60-mm dishes were given $5 \mu \mathrm{M}$ CUR, medium was removed $0,4,8,12,24,48,72$ and $96 \mathrm{~h}$ later, and spectra were measured (scanning mode 200-600 nm). Curcumin absorbs maximally near $430 \mathrm{~nm}$.

\section{HPLC analysis}

The High Pressure Liquid Chromatography (HPLC) studies were performed with a Hewlett-Packard (HP) 1050 HPLC system and Chemstation software. The stationary phase consisted of Zorbax Eclipse Plus column (Phenyl Hexyl, 4.6 x 150 mm, $95 \AA$ pore size, pH range 2-9, Agilent Technologies, Santa Clara, CA) along with a compatible Zorbax Eclipse Plus Phenyl Hexyl precolumn. The mobile phase was $45 \%$ acetonitrile and $55 \%$ buffer at $\mathrm{pH} 3.0$ (1 \% acetic acid). The $\mathrm{pH}$ was adjusted with triethanolamine (approximately $0.4 \mathrm{ml} / \mathrm{L}$ ). The run time was $15 \mathrm{~min}$, the column was maintained at $30{ }^{\circ} \mathrm{C}$, flow rate was $1.0 \mathrm{ml} / \mathrm{min}$, injection volume was $10 \mu \mathrm{l}$, and detection wavelength was $420 \mathrm{~nm}$. Under these chromatographic conditions curcumin eluted with a retention time of 6-9 $\mathrm{min}$. The elution order was $\mathrm{BDMC}<\mathrm{DMC}<$ curcumin. For best results the column was conditioned by running the mobile phase with the described composition at a flow rate of $1 \mathrm{ml} / \mathrm{min}$ for one hour. The organic modifier and the buffer component used were HPLC grade.

Standards containing all three curcuminoids (curcumin, DMC, and BDMC) were prepared across a concentration range between 0.025 and $10 \mu \mathrm{g} / \mathrm{ml}$ in DMSO. DMSO was used in the standard curve because of curcumin's limited stability in aqueous buffers at neutral $\mathrm{pH}$. The standard curve was found to be linear across the entire range. The limit of detection for all three curcuminoids was $0.025 \mu \mathrm{g} / \mathrm{ml}$, although the limit of quantitation was determined to be $0.1 \mu \mathrm{g} / \mathrm{ml}$ as the accuracy below $15 \%$ of the theoretical concentration was deemed unacceptable. The precision of the method remained below $10 \%$ of the mean at all levels for curcumin, down to $0.05 \mu \mathrm{g} / \mathrm{ml}$ for $\mathrm{DMC}$, and down to $0.1 \mu \mathrm{g} / \mathrm{ml}$ for BDMC. The standard curve data are in Additional file 1.

\section{Data analysis}

For measurements of circadian rhythms in mPER2 expression, total bioluminescence measurements from each dish were collected every hour for up to 4 days. After background subtraction, each time series was detrended by subtracting a 24-h running average. For 
continuous imaging of mitotic and apoptotic rates the cell counts taken from each image frame at 5-min intervals were summed into 1-h bins. The average hourly rates for each day were compared by two-tailed Student's $t$-test and ANOVA. The dominant period within each averaged time series was found by Fast Fourier Transform (FFT) analysis (Origin, OriginLab). Circular statistics of circadian rhythms in apoptotic and mitotic events (Rayleigh test for randomness) were performed using Oriana software (Kovach Computing Services), and the mean phase vector was used to indicate the phase of rhythms. Period estimates of rhythms were determined using the Lomb-Scargle Periodogram MATLAB program LOMB, FFT, and the Maximum Entropy Method (MEM, kSpectra Toolkit, SpectraWorks). When multiple peaks were found by MEM the peak within the circadian range (19-29 h) was used as the most precise measure of the circadian rhythm.

\section{Results}

Circadian rhythms persist at low curcumin concentrations The C6 rat glioma cell line was selected to test for an effect of the circadian clock on curcumin's anti-cancer properties because it displays circadian rhythms in expression of the core circadian clock gene $m P e r 2$ in cell cultures [40] and in tumorsphere cultures [39]. Curcumin decreases NF-kB activation, inhibits $\mathrm{C} 6$ cell proliferation, and induces cell death. We treated $\mathrm{C} 6$ cells with a low dose of curcumin (CUR) to cause limited but significant cell death over several days while allowing enough cells to remain for measurements [40]. Also, because curcumin acts on many intracellular signaling pathways [41] it was important to use a dosage that would not suppress the molecular mechanism of the circadian oscillator.

We used C6 cells stably transfected with a reporter gene that generates a fusion protein of mPER2 and firefly luciferase under control by the $m P e r 2$ gene promoter [39]. Circadian clock cells in cultures of these
mPer2::mPer2:luc C6 cells were synchronized with a 2-h forskolin treatment. Starting $12 \mathrm{~h}$ later, to allow acute forskolin effects to subside, medium was exchanged with medium containing curcumin dissolved in 0.02 or $0.04 \%$ DMSO for 5 and $10 \mu \mathrm{M}$ curcumin, respectively. The DMSO concentration was well below the threshold of $10 \%$ for toxic effects on colon cancer cells [42], and the threshold of $0.1 \%$, below which solutions can be injected safely into the vitreous of the rat eye without affecting retinal neurons [43]. This pulse of curcumin was intended to mimic a single delivery of the drug to a cancer patient either intravenously or intracerebrally. Similar to what occurs in the body, it was expected to be degraded in vitro over the next few hours based on the known properties of curcumin $[44,45]$.

C6 cell cultures in medium with $10 \%$ FBS are reported to have a 23.5 -h circadian rhythm when measured with a destabilized luciferase reporter gene controlled by the $m P e r 2$ promoter [40]. Similarly, in a previous study we detected a 25.2 -h bioluminescence rhythm in a C6 culture expressing the mPER2-LUC fusion protein, according to Lomb-Scargle Periodogram (LS) analysis $(p<0.001)$ [46]. The mPer2::mPer2:luc C6 cells also expressed circadian rhythms in cultures given $5 \mu \mathrm{M}$ CUR (Fig. 1a). For cultures treated with $5 \mu \mathrm{M}$ CUR the average period was estimated as $24.48 \mathrm{~h}$ by LS $(p<0.001)$ (Fig. 1b) and $24.47 \mathrm{~h}$ by FFT.

\section{Long-term effects of curcumin on mitosis and cell death}

Because circadian rhythms persisted after low-dose curcumin treatments, we synchronized the circadian clock cells in C6 cultures and examined the pattern of individual mitotic and apoptotic events for any effects from curcumin or the circadian clock. To determine whether the $5 \mu \mathrm{M}$ curcumin treatment was sufficient to produce anticancer effects on $\mathrm{C} 6$, and whether a higher dose would be more useful for this study, C6 cells were monitored continuously by digital video imaging of cell cultures. To identify ongoing cell division and cell death
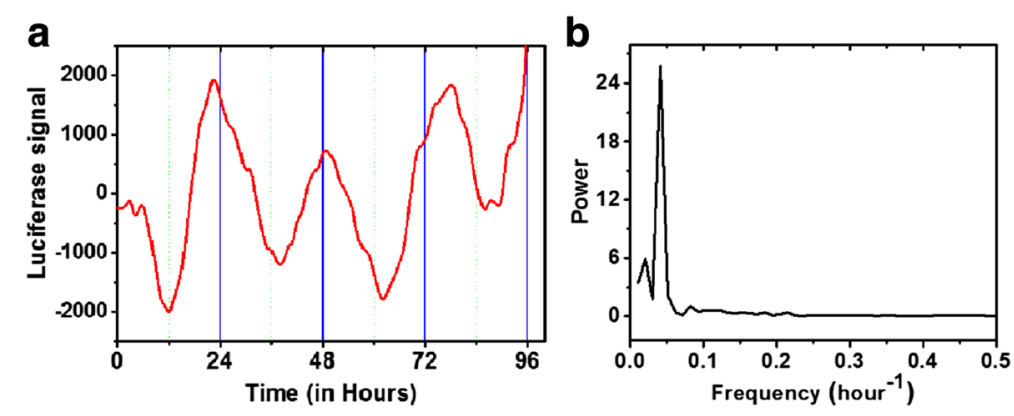

Fig. 1 Circadian rhythms in mPer2 clock gene expression persist after treatment with $5 \mu \mathrm{M}$ curcumin. (a) Signal from the mPer2::mPer2:Iuc reporter gene after a forskolin pulse used to synchronize cellular circadian oscillators is shown as the hourly integrated light signal (relative light units averaged from 4 independent cultures). (b) A significant period of $24.48 \mathrm{~h}$ was detected by Lomb-Scargle Periodogram analysis ( $p<0.001$ ) is shown in the frequency spectrum 
events in cultures time-lapse imaging (TLI) was performed using 5-min intervals between frames for up to 5 days, after synchronizing cells with forskolin and then treating with curcumin $12 \mathrm{~h}$ later. All events were counted from a single field-of-view which represented the cell events occurring in the dish (Additional file 2). The culture dish and microscope remained for days in a sealed incubator without disturbance. During TLI, there was initially an average of $23.57 \pm 7.03$ (SD) cells in the field-of-view (range 18 to $30, n=15$ cultures).

Distinct mitotic and apoptotic events were visible and counted following exposure to 0,5 , and $10 \mu \mathrm{M}$ CUR (Fig. 2). When mitotic events during day 1 of imaging were compared, $10 \mu \mathrm{M}$ was significantly more effective at suppressing cell division than $5 \mu \mathrm{M}$ (ANOVA, $F=$ 4.537, Fisher post hoc test, $p=0.0148$ ) and the control $(p=0.0216)$ (Fig. 2a). The $5 \mu \mathrm{M}$ group was, however, not significantly different from the control $(p=0.806)$. When the total mitotic events for the first four days were examined, $10 \mu \mathrm{M}$ again resulted in a significant suppression of mitosis $(p=0.0485)$ relative to control $(0 \mu \mathrm{M}: 62.67 \pm 36.439, n=6$; $5 \mu \mathrm{M}: 60.00 \pm 30.470, n=6$; $10 \mu \mathrm{M}: 15.00 \pm 0.358, n=3)$. By day 4 ( $5^{\text {th }}$ day in culture), cell confluence in the control dishes limited our ability to detect cell division events, so they were not counted.

When the apoptotic events occurring in the 0,5 , and $10 \mu \mathrm{M}$ groups during day 1 were compared, $10 \mu \mathrm{M}$ produced significant cell death $(F=18.751, p<0.001)$, but not $5 \mu \mathrm{M}$ (Fig. 2b). However, when total apoptotic events over days $1-4$ were compared $(\mathrm{F}=6.398, p=0.0128)$ the $5 \mu \mathrm{M}$ treatment caused significant cell death $(p=0.00384)$. Cell death rates were overall lower in $10 \mu \mathrm{M}$-treated cells, and more cell death occurred in the first day.

\section{Circadian modulation of curcumin effects on mitosis and cell survival}

To determine whether ongoing events of cell division and cell death in cultures exposed to curcumin are modulated by circadian timing, we measured the period and phase of any significant circadian rhythms (Fig. 3). Because individual events within the field-of-view were few the data were pooled from all cultures in each treatment group. According to LS analysis, a significant circadian rhythm in mitosis was detected in the control culture (Table 1). Most rhythms were similarly identified by FFT.

To provide a more precise estimate of the circadian period than what LS or FFT can provide we used the Maximum Entropy Method to find periods with greater resolution. According to MEM the untreated cultures displayed an average period of $21.3 \mathrm{~h}$ for mitotic events. This rhythm in cell division was similar to the doubling time of $22 \mathrm{~h}$ reported for C6 cells [47], suggesting that the forskolin treatment may have synchronized individual cell cycles. The $10 \mu \mathrm{M}$ CUR-treated cultures displayed a $20.5-\mathrm{h}$ period. Thus, circadian rhythms were observed in the mitotic events of the control and $10 \mu \mathrm{M}$ cultures (Fig. 3a, c), but not in the $5 \mu \mathrm{M}$ group (Fig. 3b). In the presence of $5 \mu \mathrm{M}$ CUR the cell division cycles and circadian rhythms appeared to be uncoupled. Mitosis displayed a rhythm of about $15 \mathrm{~h}$, and these shorter ultradian rhythms (defined here as having periods less than $18 \mathrm{~h}$ ) may have resulted from curcumin acting on cell cycle oscillations. To further test the periods of these cultures, we analyzed the mitotic events with FFT, which yielded periods of $21.3 \mathrm{~h}$ for the control group, $15.0 \mathrm{~h}$ for $5 \mu \mathrm{M}$, and $18.3 \mathrm{~h}$ for the $10 \mu \mathrm{M}$ group.

Apoptotic events occurring in the cell cultures were analyzed to detect any circadian rhythms. A rhythm with a period of $18.9 \mathrm{~h}$ was detected in the untreated group (Fig. 3d), which is at the edge of a typical circadian range of $19-30 \mathrm{~h}$ (Table 1). The apoptotic events occurring in $5 \mu \mathrm{M}$ CUR-treated cells followed a circadian rhythm with a period of $22.3 \mathrm{~h}$ (Fig. 3e). All the period estimates for this treatment group fell in the circadian range (Table 1). Circadian rhythms were absent in $10 \mu \mathrm{M}$
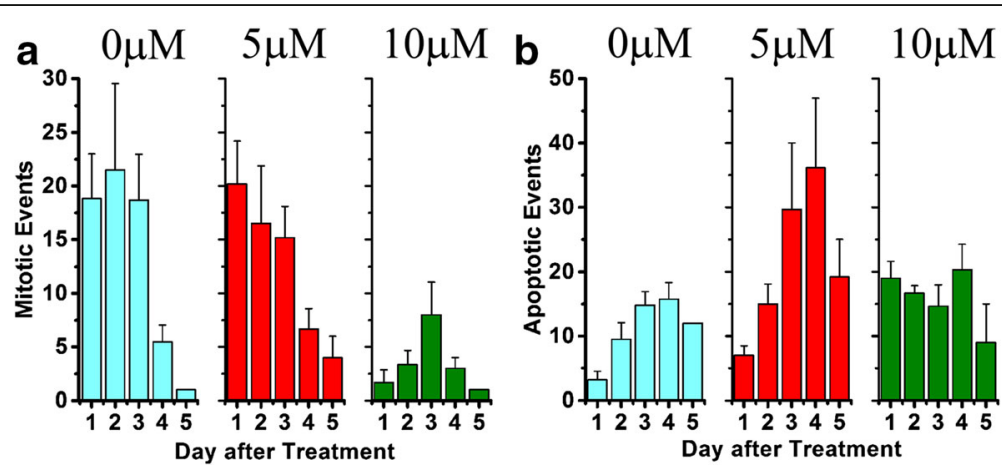

Fig. 2 Effects of curcumin on mitosis and apoptosis of C6 glioma cells. Suppression of mitotic rate (a) and induction of cell death rate (b) at two curcumin concentrations. Average hourly rates were imaged in single fields-of-view for 5 days after a forskolin pulse and a single curcumin treatment 


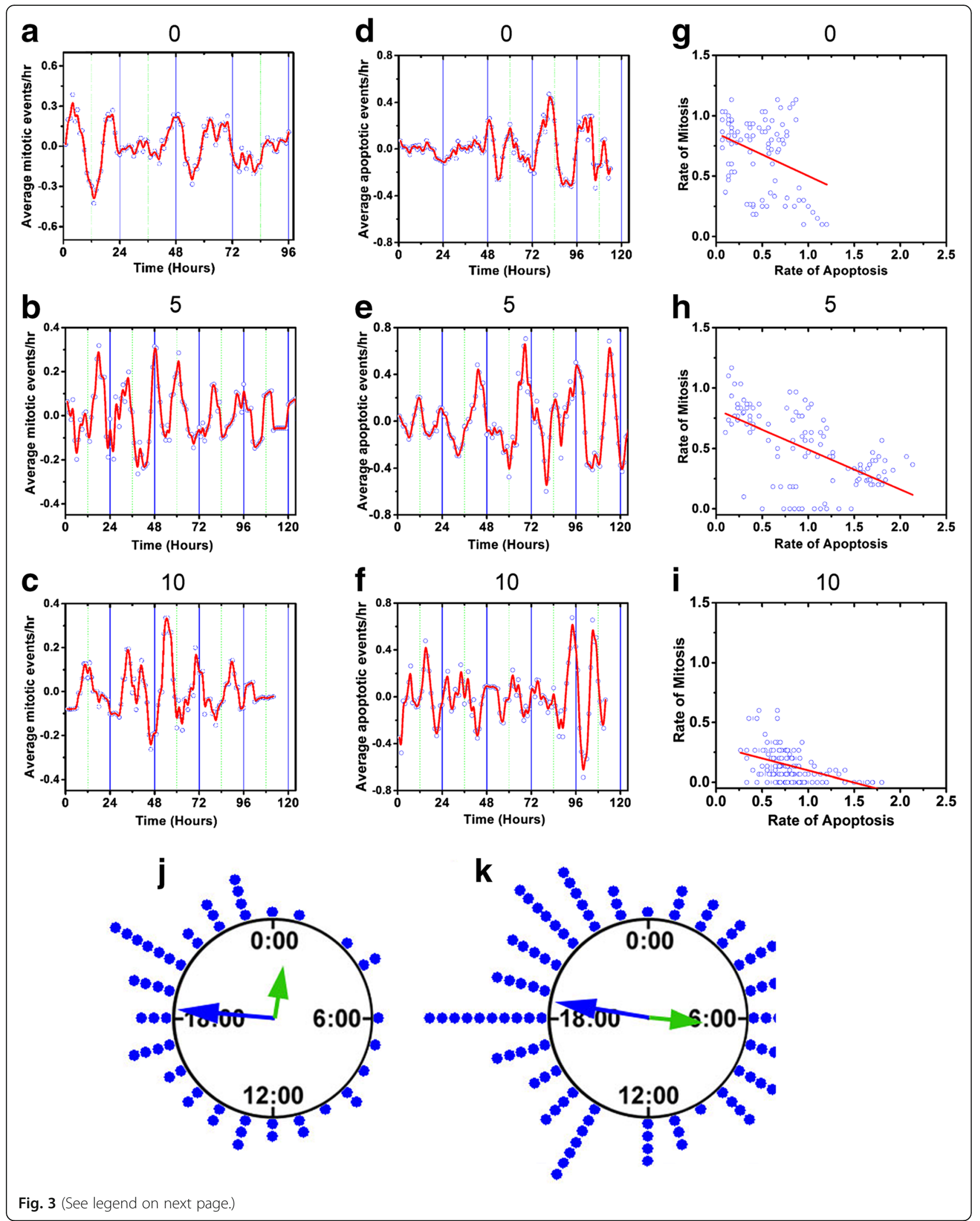


(See figure on previous page.)

Fig. 3 Circadian clock regulation of curcumin efficacy. a-c: Mitotic events in C 6 cultures showed circadian rhythms in 0 and $10 \mu M$ but not $5 \mu M$ CUR. d-f: Cell death rates (apoptotic events/hr) displayed circadian rhythms in 0 and 5 but not $10 \mu \mathrm{M}$ CUR (blue circles: events, red line: after adjacent averaging). $\mathbf{g}$-i: Apoptotic and mitotic rates were inversely correlated as shown by linear regressions. $\mathbf{j}, \mathbf{k}$ : The phase of cell death events displayed significant clustering $(p<0.001)$ in 5 MM CUR on days 2 and 3 (left and right, Z = 14.62 and 7.399 by Rayleigh Test, respectively). Long arrow indicates phase of mean vector. Short arrow (green) indicates peak of mPER2::LUC rhythm from Fig. 1. The curcumin treatment began at 12:00 AM (0:00) on Day 1. Each dot indicates 2 events

CUR-treated cells (Fig. 3f), which instead had an ultradian rhythm of 11-14 h (Table 1). Circadian rhythms in apoptosis persisted in the 5 but not $10 \mu \mathrm{M}$ cultures, indicating that the clock can modulate cell death at the lower curcumin dosage.

Because mitotic and apoptotic rates appeared to reach their maxima at different times, we examined this relationship in the untreated, 5, and $10 \mu \mathrm{M}$ groups. The apparent inverse relationship between apoptotic and mitotic events was confirmed by a linear correlation test comparing the two time-series data sets: Pearson's correlation $r$ values were $-0.350,-0.599$, and -0.437 for the 0 , 5, and $10 \mu \mathrm{M}$ treatments, respectively (Fig. $3 g-\mathrm{i}$ ). The mitotic rate was highest in the untreated group as apoptotic events were fewer in that group, while the $10 \mu \mathrm{M}$ group had lower mitotic rates and higher rates of apoptosis during the initial days of treatment.

Along with the period analyses, we also examined the phase relationships between the mPER2 rhythm shown in Fig. 1 and the mitotic and apoptotic rhythms. We applied circular statistics to identify significant clustering of apoptotic events in curcumin-treated groups over the first three 24-h cycles of imaging. When examining the timing of these events relative to the forskolin treatment, significant clustering was observed at 18.3 and $18.6 \mathrm{~h}$ during the $2^{\text {nd }}$ and $3^{\text {rd }}$ days of imaging, respectively, in the $5 \mu \mathrm{M}$ group (Fig. 3j, k). When comparing these phases with the mPER2 rhythm, they occurred on the rising phase, about 6 and $11 \mathrm{~h}$ before the corresponding circadian peaks in mPER2 protein expression.

There was no significant clustering of cell death events in the $10 \mu \mathrm{M}$ group, in agreement with the loss of circadian periodicity of apoptosis. The phase of cell deaths in the control group $(0 \mu \mathrm{M})$ was significantly clustered $(p<0.05)$ on the second day, but the mean vector was not significantly different from that of the $5 \mu \mathrm{M}$ group, indicating that curcumin did not produce a measurable phase shift of the rhythm (control: $16: 24$ with a $99 \%$ confidence interval of $12: 31$ and $20: 17 \mathrm{~h}$ on days 2 and 3, respectively; $5 \mu \mathrm{M}$ : $18: 18$ with $99 \%$ confidence intervals of $16: 34$ and 20:03 h on days 2 and 3). There was no significant clustering of apoptotic or mitotic events in the remaining groups.

As an additional test of whether cell death events vary according to the circadian cycle, we quantified the percentage of cells expressing activated caspase-3, a late apoptotic marker $[48,49]$ in C6 cells given $5 \mu$ M CUR. Three times were selected to coincide with the second peak, the following trough, and the third peak observed in the rhythm in apoptosis (Fig. 3e). The three phases examined showed relative differences in cell death matching the oscillations in apoptotic events in the time series (Fig. 4a). The percentage of apoptotic cells was $61.15 \pm 0.03 \%$ at the $45^{\text {th }} \mathrm{hr}$ and $47.62 \pm 0.04 \%$ at the $69^{\text {th }} \mathrm{hr}$, which are both peak phases in the circadian rhythm of death rate. During the trough phase $\left(57^{\text {th }} \mathrm{hr}\right)$ the percentage of apoptotic cells declined to $23.50 \pm$ $0.02 \%$. Visibly, there were more cells stained with anticaspase 3 antibody at the peak phases (Fig. $4 \mathrm{~b}$, I and II) than at a trough phase (Fig. 4b, III and IV).

\section{Stability and localization of curcuminoids and their metabolites}

Although curcumin is being tested as an anticancer drug in a number of clinical trials $[5,50]$, its use is limited because of fast degradation at neutral and alkaline $\mathrm{pH}$ and poor tissue absorption [51, 52]. Studies have shown that curcumin is relatively more stable in culture media containing $10 \%$ fetal bovine serum (FBS), compared to phosphate buffer or culture media without FBS [53]. Despite the expected loss of curcumin, our TLI data showed that apoptosis continued for several days after initial treatment with 5 or $10 \mu \mathrm{M}$ CUR. Using a spectrophotometer we found evidence of curcumin in culture

Table 1 Period analysis of C6 cell cultures

\begin{tabular}{|c|c|c|c|c|c|c|c|}
\hline \multirow{2}{*}{$\begin{array}{l}\text { Curcumin } \\
\text { Treatment }(\mu \mathrm{M})\end{array}$} & \multirow{2}{*}{$\begin{array}{l}\text { Imaging } \\
\text { Duration (hrs) }\end{array}$} & \multicolumn{3}{|c|}{ Mitosis } & \multicolumn{3}{|c|}{ Apoptosis } \\
\hline & & $\overline{\mathrm{LS}}$ & FFT & MEM & $\overline{\mathrm{LS}}$ & FFT & MEM \\
\hline 0 & 114 & 22.6 & 21.3 & 21.3 & 18.8 & 21.3 & 18.9 \\
\hline 5 & 135 & 14.9 & 15.0 & Non-circadian & 22.3 & 23.3 & 24.4 \\
\hline 10 & 112 & 18.5 & 18.3 & 20.5 & 11.1 & 14.2 & Non-circadian \\
\hline
\end{tabular}

All period estimates are in hours. LS: Lomb-Scargle Periodogram, FFT: Fast Fourier Transform, MEM: Maximum Entropy Method. All LS results were significant $(p<0.001)$. "Non-circadian" indicates neither of the two most powerful peaks of the frequency spectra fell in the circadian range (19-29). 

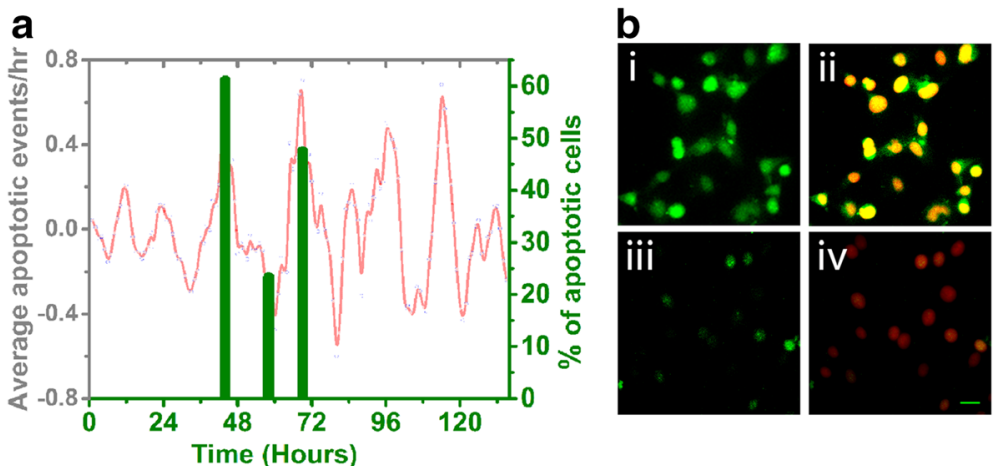

Fig. 4 Expression of activated caspase-3 according to phase of the circadian cycle. a: Percentage of apoptotic cell counts at 45, 57, and 69 h after adding $5 \mu \mathrm{M}$ CUR. The relative changes in the percent cell death agreed with the peaks and trough in the circadian rhythm of death rate for cells treated with $5 \mu \mathrm{M}$ CUR (red line, from Fig. 3e, shown here for comparison). b: Immunostaining cleaved caspase-3 in apoptotic cells (green) at two circadian phases, the peak at $45 \mathrm{~h}$ (i) and the trough at $57 \mathrm{~h}$ (iii), after $5 \mu \mathrm{M}$ CUR treatment; ii and iv: The same cells merged with Hoechst nuclear staining (red). Scale bar $=10 \mu \mathrm{m}$

media during the days the cells were imaged (Fig. 5). A standard curve was created at curcumin's maximal absorbance near $430 \mathrm{~nm}$ [54]. Nevertheless, curcumin levels declined within the first day, becoming nearly undetectable (Fig. 5a). During the first $24 \mathrm{~h}$, the curcumin declined with a half-life of about $1.7 \mathrm{~h}$ by degrading or entering cells (Fig. $5 \mathrm{a}$ inset). The curcumin levels in media also showed an unexpected small increase after the second day.
Autofluorescence imaging of curcumin's cellular distribution in live cells showed that curcumin is present in the nucleus one hour after application (Fig. 5b). Although curcumin levels decreased considerably in the culture media, curcuminoids were visible in C6 cells for at least $24 \mathrm{~h}$ after application (Fig. 5c). The autofluorescence study was performed in live C6 cells $1 \mathrm{~h}$ and $24 \mathrm{~h}$ after curcumin treatment. To confirm the

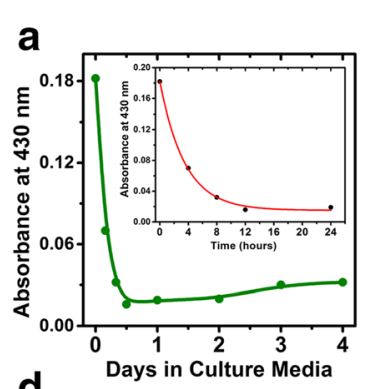

d

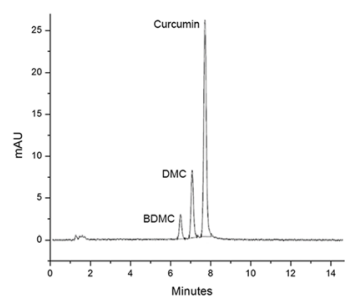

b
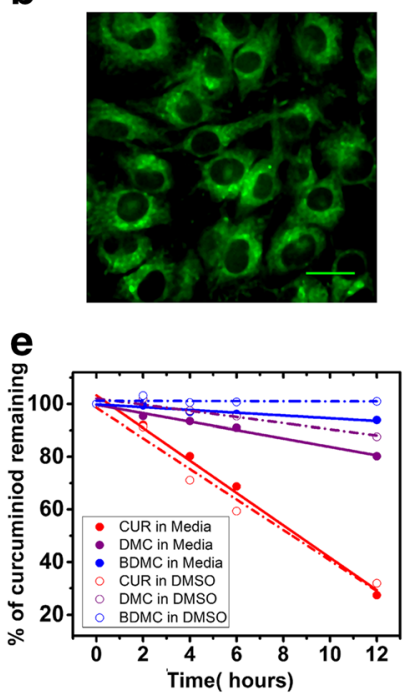

C

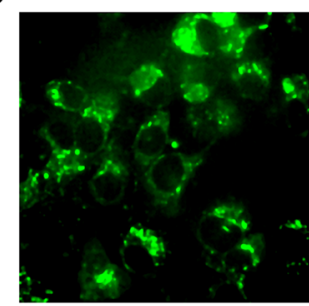

f

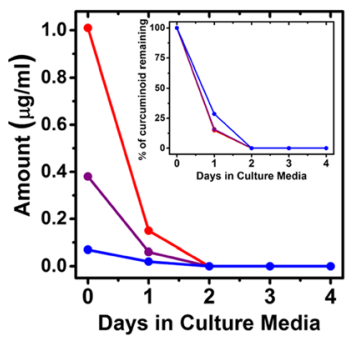

Fig. 5 Stability of the 3 curcuminoids in cell culture. Curcumin degraded with a half-life of about $1.7 \mathrm{~h}$ in cell culture medium with cells present. $\mathbf{a}$ : Curcumin absorbance in culture medium with C6 cells for 4 days measured with a spectrophotometer. Inset: Absorbance during the first 24 h. b: $5 \mu \mathrm{M}$ CUR produced fluorescence in live C6 cells within $1 \mathrm{~h}$ after its introduction. Scale bar $=5 \mu \mathrm{m}$. c: Curcuminoid fluorescence persisted in cells for at least $24 \mathrm{~h}$ (same scale as B). $\mathbf{d}$ : A representative HPLC chromatogram showing complete baseline separation of the 3 curcuminoids from cell culture medium containing $0.3 \%$ DMSO. The first group of merged peaks near 1.6 min represents the chromophoric compounds from the media. The second peak at $6.45 \mathrm{~min}$ is BDMC, the peak at $7.04 \mathrm{~min}$ is that of DMC, and the last peak at $7.68 \mathrm{~min}$ is that of curcumin. (mAU = milliabsorbance units). This is the same CUR preparation used for treating the cells. e: HPLC measurements show curcuminoids DMC and BDMC persist longer than curcumin in cell culture medium and degrade even slower in DMSO. f: HPLC measurements of curcuminoids in culture medium with C6 cells present for 5 days. Inset: The same data normalized to initial levels. Line colors are as in $\mathbf{e}$. 
nuclear localization of curcumin $24 \mathrm{~h}$ after curcumin treatment, cells were fixed and stained with Hoechst nuclear stain (Additional file 3). It was observed that curcumin was present in the nucleus and was concentrated in distinct intra-nuclear sites, as described previously [55].

The curcumin treatment used in the study contained the additional congeners DMC and BDMC (Fig. 5d), which may have contributed to the apoptotic or mitotic effects. The relative amount of curcumin present in the CUR treatment was similar to that reported by the manufacturer $(\geq 65 \%)$. To better understand the potential contributions of the congeners to the cell effects we used HPLC to measure curcumin, DMC, and BDMC concentrations in cell culture medium at $0,2,4,6$ and $12 \mathrm{~h}$ after treatment. Samples containing curcuminoids in complete medium (10 \% FBS serum and $0.3 \%$ DMSO) were preserved at $-20{ }^{\circ} \mathrm{C}$ in the dark. To prevent further degradation each sample was allowed to thaw before $10 \mu \mathrm{l}$ was injected without further purification or delay.

As predicted from previous studies [56], the HPLC results indicated that curcumin degraded by over $75 \%$ within $12 \mathrm{~h}$ in culture medium at room temperature, but the two congeners degraded more slowly (Fig. 5e), around $20 \%$ for DMC and only $8 \%$ for BDMC, suggesting that they could have been responsible for cell death along with curcumin after the first day of treatment. The degradation rates of the congeners in DMSO were relatively slower than in culture media (Fig. 5e). Degradation patterns of the three curcuminoids were also measured in samples of medium from cultures containing C6 cells once per day for 4 days after the curcumin treatment (Fig. 5f). All conditions of these samples were kept similar to those of the previous TLI cultures. There was a rapid decline of curcumin in culture medium during the first $24 \mathrm{~h}$ at $37{ }^{\circ} \mathrm{C}$ (to about $15 \%$ ). DMC decreased to about $16 \%$ in the first $24 \mathrm{~h}$ of treatment, whereas BDMC declined to about $28 \%$ (Fig. $5 f$ inset).

Although the culture medium had very little curcumin or congener present, the cells retained curcuminoids, as shown in Figs. 5b and c, which could have been responsible for apoptosis and other cellular effects. To determine whether the medium retains an anti-cancer property after curcumin levels decline, we examined C6 cells treated with a conditioned medium (CM) that was withdrawn from a C6 culture one day after treatment with $5 \mu \mathrm{M}$ curcumin (Additional file 4). Significant cell death or mitotic arrest was not observed in response to $\mathrm{CM}$ treatment.

\section{Discussion}

This is the first study to examine the effects of curcumin on circadian rhythms in cancer cells and whether the circadian clock is altered by curcumin treatments.
Curcumin impacts several signaling pathways regulating the intracellular timing cycles generating circadian rhythms. These targets include STAT, PPAR $\gamma$, and NFkB that act on gene expression within the two interconnected molecular timing loops of the circadian oscillator that generate the rhythm. Nevertheless, the circadian rhythm in C6 cells persisted following the $5 \mu \mathrm{M}$ curcumin treatment that produced increased cell death days later. Although this dosage did not arrest the clock, the $10 \mu \mathrm{m}$ curcumin treatment did produce a loss of any detectable circadian rhythm in apoptosis. The absence of circadian periodicity at $10 \mu \mathrm{M}$ could have been caused by disruption of individual circadian oscillators within clock cells or the coupling between circadian clocks. Nevertheless, fast circadian oscillations in mitotic events persisted.

Perhaps the best explanation for these results is that the clock regulates cell death by increasing the probability of its occurrence at a particular phase of the circadian cycle, but treatment dosages that produce greater stimulation of the apoptotic pathway mask clock control of these events. Because the circadian rhythm in BMAL1 activity is considered a major timing output of the clock, producing rhythms in many genes, we speculate that it also modulates expression of proteins that degrade or transport curcumin [57]. It is unclear why the circadian rhythm in mitotic events was lost after applying $5 \mu \mathrm{M}$ but not $10 \mu \mathrm{M}$ curcumin. Nevertheless, the $5 \mu \mathrm{M}$ data did show a pattern resembling a disrupted population of circadian oscillators, perhaps because of fragmentation of the previously synchronized cell population into two or more rhythmic groups. Both of these concentrations were below the reported $\mathrm{IC}_{50}$ of $25 \mu \mathrm{M}$ for curcumin effects on C6 cells [58], and cells continued to proliferate during the several days of imaging, which was our intention.

Curcumin produced a delayed and persistent cell death well after it was no longer easily detectable in medium by HPLC or absorbance spectroscopy at the end of the first day after delivery. There are several possible mechanisms that can explain this sustained effect: The initial treatment altered some of the cells in a way that arrested their cell cycle and caused them to die much later. Curcumin is known to induce cell death through mitotic arrest [59], at which point cell death might begin long after the time when untreated cells would have divided. Alternatively, the cells may have continued to divide, but the treatment caused a change in the viability of the cells that was also present in the progeny of the treated cells. For example, curcumin can produce epigenetic alterations that may promote cancer cell death [60].

Another intriguing possibility is that because curcumin is lipophilic it was entrapped in cell membranes where it 
was protected from degradation and then released into the cytosol, perhaps through membrane turnover, thereby killing cells much later. A similar mechanism was proposed for effects from vanillin, a curcumin degradation product with weaker anti-cancer properties [61]. This possibility is supported by the curcumin autofluorescence we observed in live cells at least $24 \mathrm{~h}$ after exposure.

We also considered the possibility that the two congeners of curcumin may have caused the delayed cell death along with curcumin or in its absence. Both DMC and BDMC persisted much longer in culture medium than curcumin, and both are reported to have anti-cancer effects, as shown in lung cancer cell lines [62, 63]. Curcumin degrades rapidly in blood and perhaps also cerebrospinal fluid, but the more persistent congeners may be responsible for the systemic effects reported in some animal studies [64]. Interestingly, BDMC also inhibits cancer cell metastasis [65]. DMC was reported to oxidize more slowly than curcumin at physiological $\mathrm{pH}$, persisting for at least a day, but BDMC was resistant to oxidation [66], suggesting that it may have a more prolonged effect on C6 cells than the other two curcuminoids. It is also possible that some or much of the curcumin autofluorescence we and others observed in cell membranes actually originated from the congeners, which have excitation and emission spectra similar to those of curcumin [67]. By passing through this cell reservoir, the congeners might have produced delayed cell toxicity. The two curcumin congeners showed greater stability in DMSO than in cell culture medium suggesting that the nonpolar cell membrane environment might also protect curcuminoids longer than culture medium or other aqueous solutions.

Finally, we did not investigate curcumin's degradation products in C6 cells, but some of these have known anti-cancer properties [62, 68, 69]. For example, tetrahydrocurcumin is an early product that would be formed in aqueous media, such as after intravascular injection [64], and it may have contributed to cell death in the C6 cultures. Similarly, the more lipophilic degradation products may have accumulated in cell membranes, producing a delayed response. Because the medium conditioned with C6 cells for $24 \mathrm{~h}$ did not increase cell death, any curcumin, congeners, or degradation products present in the medium after the first day are not likely to have had much effect on cell survival. Instead, curcuminoids bound to or integrated into cell membranes are the most likely causal agents.

The C6 mitotic and apoptotic events displayed a significant inverse relationship in 0,5 , and $10 \mu \mathrm{M}$ curcumin, indicating a coordinated timing between these two properties in cultures. Circadian clocks can control the cell division cycle at several checkpoints, most notably through p21 regulation by the core clock protein BMAL1 [70, 71].
This coupling is, however, variable as shown previously when the two types of rhythms were manipulated in Lewis lung carcinoma cells to oscillate with different periods [72]. Unlike circadian clocks, metabolic and hormonal signals can readily arrest or initiate mitosis, and the greater lability of the cell cycle period impairs its ability to provide accurate timing. Furthermore, the circadian clock is compensated to maintain a more constant period as temperature changes. We detected about a 2-h difference in period between mitotic and apoptotic oscillations in the control culture suggesting that the two rhythmic processes are not tightly coupled. Nevertheless, the correlations we detected indicate that the phase of the cell cycle can provide an estimate of circadian phase in some cancer cell types and may be useful for predicting when curcumin is most effective. In the C6 cultures, cell death was observed most often when mitotic rates were minimal.

The highest apoptotic rate was about 6-11 h before the peak of mPER2 expression in C6 cells, suggesting that there is a time of day when curcumin treatment would be most effective for treating patients. To use this result to optimize delivery of curcumin, encapsulated curcumin or curcumin nanoparticles [73] it will be necessary to predict the circadian phase of the cancer cells within the tumor. Additional studies are needed to determine whether human tumors with a functioning circadian clock are entrained by the body's daily rhythms in cortisol, melatonin or other signals, resulting in a predictable maximum in PER2 expression for timing delivery of curcumin or similar drugs. However, any daily rhythms in curcumin's absorption and degradation also need to be considered.

Curcumin analogs are more stable alternatives to curcumin [74] and should be tested to determine whether they too are most effective at this circadian phase. Furthermore, chemically distinct chemotherapeutic agents that act through pathways blocked by curcumin, such as NFkB [58], may be most effective at this phase in gliomas and other cancer cell types. Curcumin's reported ability to prevent cancers may also be optimal at the time of day corresponding with this phase of highest sensitivity, which may be estimated from PER2 circadian rhythms measured in non-cancer cells of healthy individuals.

\section{Conclusion}

Glioma cells are most vulnerable to the lethal effects of curcuminoids at a particular phase of the circadian cycle. Curcuminoids bind to cell membranes and accumulate in cell nuclei, possibly serving as a reservoir providing delayed release and sustained anti-cancer effects. Cancer patient care should include time-of-day curcumin dosing, to exploit the sensitive phase, and should consider treatment with the curcumin congeners because of their stability under physiologically relevant conditions. 


\section{Additional files}

Additional file 1: Table S1. Curcuminoid analysis (standard curve parameters). Cited in HPLC analysis section of the Methods. (PDF $95 \mathrm{~kb}$ )

Additional file 2: Effects of curcumin on cell division and cell death rates. Cited in long-term time-lapse cell imaging section of the Results. Shows individual frames from videos of C6 mitosis and cell death. (PPTX $1258 \mathrm{~kb}$ )

Additional file 3: Autofluorescence of curcumin in C6 cells. Cited in the Results section. Microscope images of curcumin autofluorescence in C6 cells $24 \mathrm{~h}$ after exposure. (PPTX $966 \mathrm{~kb}$ )

Additional file 4: Effects on C6 cells from CUR-conditioned medium. Cited in the Results section. Shows the lack of a significant effect from 24-h conditioned medium. (PPTX $161 \mathrm{~kb}$ )

\section{Abbreviations}

ANOVA: Analysis of variance; AP-1: Activator protein-1;

BDMC: Bisdemethoxycurcumin; CCD: Charge-coupled device;

CM: Conditioned medium; CUR: Curcumin; DAPI: 4',6-diamidino-2phenylindole dihydrochloride; DMC: Demethoxycurcumin; DMEM: Dulbecco's Modified Eagle Medium; DMSO: Dimethyl sulfoxide; FBS: Fetal bovine serum; FFT: Fast Fourier Transform; FM: Final medium; HEPES: N-2hydroxyethylpiperazine-N'-2'-ethanesulfonic acid; HPLC: High pressure liquid chromatography; LED: Light-emitting diode; LS: Lomb-Scargle; MEM: Maximum Entropy Method; NF-kB: Nuclear factor-kB; PML: Promyelocytic leukemia protein; PPAR- $\gamma$ : Peroxisome proliferatoractivated receptor- $\gamma$; SIRT1: Sirtuin 1; TLI: Time-lapse imaging

\section{Acknowledgements}

We thank Cameron McLaughlin for editorial help with the manuscript.

\section{Funding}

Support was provided by a BGSU Building Strength Grant provided through the Faculty Research Committee, which had no role in the design of the study or data collection, analysis, or interpretation or writing of the manuscript.

\section{Availability of data and materials}

Data files used in this study will be made available on-line in the openaccess Dryad Digital Repository http://datadryad.org

\section{Authors' contributions}

AS contributed towards conception and design, acquisition of data, analysis and interpretation of data, and drafting and revising the manuscript. VPS contributed towards acquisition of data, planning experiments, and revising the manuscript draft. ABS contributed towards acquisition of HPLC data, analysis and interpretation of data, and revising the manuscript draft. MCS contributed towards analysis and interpretation of data, planning experiments, and revising the manuscript. KS contributed towards acquisition of data and revising the manuscript. MEG contributed towards conception and design, acquisition of data, analysis and interpretation of data, and drafting and revising the manuscript. All authors read and approved the final manuscript.

\section{Competing interests}

The authors declare that they have no competing interests.

\section{Consent for publication}

Not applicable.

\section{Ethics approval and consent to participate}

Not applicable.

\section{Author details}

'Department of Biological Sciences, Bowling Green State University, 217 Life Science Building, Bowling Green, OH 43403, USA. '2Life Sciences Institute, University of Michigan, Ann Arbor, MI 48109, USA. ${ }^{3}$ Department of Pharmaceutical Sciences, University of Findlay, Findlay, $\mathrm{OH} 45840$, USA.
Received: 11 April 2016 Accepted: 15 September 2016

Published online: 29 September 2016

\section{References}

1. Maheshwari RK, Singh AK, Gaddipati J, Srimal RC. Multiple biological activities of curcumin: a short review. Life Sci. 2006;78(18):2081-7. doi:10.1016/j.lfs.2005.12.007.

2. Shishodia S, Chaturvedi MM, Aggarwal BB. Role of curcumin in cance therapy. Curr Probl Cancer. 2007:31(4):243-305.

3. Marathe S, Negi VD, Chakravortty D. Curcumin! Spicy panacea for all-friend or foe. Vaccine. 2009:28(2):291-2. doi:10.1016/j.vaccine.2009.10.056.

4. Lopez-Lazaro M. Anticancer and carcinogenic properties of curcumin: considerations for its clinical development as a cancer chemopreventive and chemotherapeutic agent. Mol Nutr Food Res. 2008;52 Suppl 1:S103-27.

5. Shehzad A, Wahid F, Lee YS. Curcumin in cancer chemoprevention: molecular targets, pharmacokinetics, bioavailability, and clinical trials. Arch Pharm (Weinheim). 2010;343(9):489-99. doi:10.1002/ardp.200900319.

6. Wilken R, Veena MS, Wang MB, Srivatsan ES. Curcumin: A review of anticancer properties and therapeutic activity in head and neck squamous cell carcinoma. Mol Cancer. 2011:10:12. doi:10.1186/1476-4598-10-12.

7. Zhuang W, Long L, Zheng B, Ji W, Yang N, Zhang Q, et al. Curcumin promotes differentiation of glioma-initiating cells by inducing autophagy. Cancer Sci. 2012;103(4):684-90. doi:10.1111/j.1349-7006.2011.02198.x.

8. Liu E, Wu J, Cao W, Zhang J, Liu W, Jiang $X$, et al. Curcumin induces G2/M cell cycle arrest in a p53-dependent manner and upregulates ING4 expression in human glioma. J Neurooncol. 2007:85(3):263-70.

9. Pestereva E, Kanakasabai S, Bright JJ. PPARgamma agonists regulate the expression of stemness and differentiation genes in brain tumour stem cells. Br J Cancer. 2012;106(10):1702-12. doi:10.1038/bjc.2012.161.

10. Fong D, Yeh A, Naftalovich R, Choi TH, Chan MM. Curcumin inhibits the side population (SP) phenotype of the rat C6 glioma cell line: towards targeting of cancer stem cells with phytochemicals. Cancer Lett. 2010;293(1):65-72. doi:10.1016/j.canlet.2009.12.018.

11. Dhandapani KM, Mahesh VB, Brann DW. Curcumin suppresses growth and chemoresistance of human glioblastoma cells via AP-1 and NFkappaB transcription factors. J Neurochem. 2007;102(2):522-38.

12. Gao X, Deeb D, Jiang H, Liu YB, Dulchavsky SA, Gautam SC. Curcumin differentially sensitizes malignant glioma cells to TRAIL/Apo2L-mediated apoptosis through activation of procaspases and release of cytochrome $c$ from mitochondria. J Exp Ther Oncol. 2005;5(1):39-48.

13. Nagai S, Kurimoto M, Washiyama K, Hirashima Y, Kumanishi T, Endo S. Inhibition of cellular proliferation and induction of apoptosis by curcumin in human malignant astrocytoma cell lines. J Neurooncol. 2005;74(2):105-11. doi:10.1007/s11060-004-5757-1

14. Panchal HD, Vranizan K, Lee CY, Ho J, Ngai J, Timiras PS. Early anti-oxidative and anti-proliferative curcumin effects on neuroglioma cells suggest therapeutic targets. Neurochem Res. 2008;33(9):1701-10. doi:10.1007/s11064-008-9608-x

15. Zanotto-Filho A, Braganhol E, Edelweiss MI, Behr GA, Zanin R, Schroder R, et al. The curry spice curcumin selectively inhibits cancer cells growth in vitro and in preclinical model of glioblastoma. J Nutr Biochem. 2012;23(6): 591-601. doi:10.1016/j.jnutbio.2011.02.015.

16. Su Y, Qiu Q, Zhang X, Jiang Z, Leng Q, Liu Z, et al. Aldehyde dehydrogenase 1 A1-positive cell population is enriched in tumor-initiating cells and associated with progression of bladder cancer. Cancer Epidemiol Biomarkers Prev. 2010;19(2):327-37. doi:10.1158/1055-9965.EPI-09-0865.

17. Ahsan H, Parveen N, Khan NU, Hadi SM. Pro-oxidant, anti-oxidant and cleavage activities on DNA of curcumin and its derivatives demethoxycurcumin and bisdemethoxycurcumin. Chem Biol Interact. 1999:121(2):161-75.

18. Hoehle SI, Pfeiffer E, Solyom AM, Metzler M. Metabolism of curcuminoids in tissue slices and subcellular fractions from rat liver. J Agric Food Chem. 2006;54(3):756-64. doi:10.1021/jf058146a.

19. Ruby AJ, Kuttan G, Babu KD, Rajasekharan KN, Kuttan R. Anti-tumour and antioxidant activity of natural curcuminoids. Cancer Lett. 1995:94(1):79-83.

20. Focan C. Marker rhythms for cancer chronotherapy. From laboratory animals to human beings. In vivo. 1995:9(4):283-98.

21. Canaple L, Kakizawa T, Laudet V. The days and nights of cancer cells. Cancer Res. 2003:63(22):7545-52

22. Granda TG, Liu XH, Smaaland R, Cermakian N, Filipski E, Sassone-Corsi P, et al. Circadian regulation of cell cycle and apoptosis proteins in mouse bone marrow and tumor. Faseb J. 2005;19(2):304-6. doi:10.1096/fj.04-2665fje. 
23. Nakagawa K, Yamamoto T, Yasuda A. Detection of the CLOCK/BMAL1 heterodimer using a nucleic acid probe with cycling probe technology. Anal Biochem. 2010;404(2):165-70. doi:10.1016/j.ab.2010.05.024.

24. Hu ML, Yeh KT, Lin PM, Hsu CM, Hsiao HH, Liu YC, et al. Deregulated expression of circadian clock genes in gastric cancer. BMC Gastroenterol. 2014;14:67. doi:10.1186/1471-230X-14-67.

25. Cadenas C, van de Sandt L, Edlund K, Lohr M, Hellwig B, Marchan R, et al. Loss of circadian clock gene expression is associated with tumor progression in breast cancer. Cell Cycle. 2014;13(20):3282-91. doi:10.4161/15384101.2014.954454.

26. Hwang-Verslues WW, Chang PH, Jeng YM, Kuo WH, Chiang PH, Chang YC et al. Loss of corepressor PER2 under hypoxia up-regulates OCT1-mediated EMT gene expression and enhances tumor malignancy. Proc Natl Acad Sci U S A. 2013. doi:10.1073/pnas.1222684110

27. Li A, Lin X, Tan X, Yin B, Han W, Zhao J, et al. Circadian gene Clock contributes to cell proliferation and migration of glioma and is directly regulated by tumor-suppressive miR-124. FEBS Lett. 2013;587(15):2455-60. doi:10.1016/j.febslet.2013.06.018.

28. Sancar A, Lindsey-Boltz LA, Gaddameedhi S, Selby CP, Ye R, Chiou YY, et al. Circadian clock, cancer, and chemotherapy. Biochemistry. 2015;54(2):110-23. doi:10.1021/bi5007354

29. Wang HM, Zhao YX, Zhang S, Liu GD, Kang WY, Tang HD, et al. PPARgamma agonist curcumin reduces the amyloid-beta-stimulated inflammatory responses in primary astrocytes. J Alzheimers Dis. 2010;20(4): 1189-99. doi:10.3233/JAD-2010-091336.

30. Wang N, Yang G, Jia Z, Zhang H, Aoyagi T, Soodvilai S, et al. Vascular PPARgamma controls circadian variation in blood pressure and heart rate through Bmal1. Cell Metab. 2008;8(6):482-91. doi:10.1016/j.cmet.2008.10.009.

31. Chung S, Yao H, Caito S, Hwang JW, Arunachalam G, Rahman I. Regulation of SIRT1 in cellular functions: role of polyphenols. Arch Biochem Biophys. 2010;501(1):79-90. doi:10.1016/j.abb.2010.05.003.

32. Miki T, Xu Z, Chen-Goodspeed M, Liu M, Van Oort-Jansen A, Rea MA, et al. PML regulates PER2 nuclear localization and circadian function. Embo J. 2012;31(6):1427-39. doi:10.1038/emboj.2012.1.

33. Asher G, Gatfield D, Stratmann M, Reinke H, Dibner C, Kreppel F, et al. SIRT1 regulates circadian clock gene expression through PER2 deacetylation. Cell. 2008;134(2):317-28. doi:10.1016/j.cell.2008.06.050.

34. Kaur G, Phillips C, Wong K, Saini B. Timing is important in medication administration: a timely review of chronotherapy research. Int J Clin Pharm. 2013;35(3):344-58. doi:10.1007/s11096-013-9749-0.

35. Griffett K, Burris TP. The mammalian clock and chronopharmacology. Bioorg Med Chem Lett. 2013;23(7):1929-34. doi:10.1016/j.bmcl.2013.02.015.

36. Sallam H, El-Serafi AT, Filipski E, Terelius Y, Levi F, Hassan M. The effect of circadian rhythm on pharmacokinetics and metabolism of the Cdk inhibitor, roscovitine, in tumor mice model. Chronobiol Int. 2015;32(5):608-14 doi:10.3109/07420528.2015.1022782.

37. Levi F, Schibler U. Circadian rhythms: mechanisms and therapeutic implications. Annu Rev Pharmacol Toxicol. 2007;47:593-628. doi:10.1146/annurev.pharmtox.47.120505.105208.

38. Filipski E, Li XM, Levi F. Disruption of circadian coordination and malignant growth. Cancer Causes Control. 2006;17(4):509-14. doi:10.1007/s10552-005-9007-4.

39. Sharma VP, Anderson NT, Geusz ME. Circadian properties of cancer stem cells in glioma cell cultures and tumorspheres. Cancer Lett. 2014;345(1):65-74. doi:10.1016/j.canlet.2013.11.009.

40. Fujioka A, Takashima N, Shigeyoshi Y. Circadian rhythm generation in a glioma cell line. Biochem Biophys Res Commun. 2006;346(1):169-74.

41. Ghosh S, Banerjee S, Sil PC. The beneficial role of curcumin on inflammation, diabetes and neurodegenerative disease: A recent update. Food Chem Toxicol. 2015;83:111-24. doi:10.1016/j.fct.2015.05.022.

42. Da Violante G, Zerrouk N, Richard I, Provot G, Chaumeil JC, Arnaud P. Evaluation of the cytotoxicity effect of dimethyl sulfoxide (DMSO) on Caco2/TC7 colon tumor cell cultures. Biol Pharm Bull. 2002;25(12):1600-3.

43. Tsai TI, Bui BV, Vingrys AJ. Dimethyl sulphoxide dose-response on rat retinal function. Doc Ophthalmol. 2009;119(3):199-207. doi:10.1007/s10633-009-9191-8.

44. Teiten MH, Dicato M, Diederich M. Hybrid curcumin compounds: a new strategy for cancer treatment. Molecules. 2014;19(12):20839-63. doi:10.3390/molecules191220839.

45. Salem M, Rohani S, Gillies ER. Curcumin, a promising anti-cancer therapeutic: A review of its chemical properties, bioactivity and approaches to cancer cell delivery. RSC Adv. 2014;4(21):10815-29. doi:10.1039/C3RA46396F.
46. Sarma A, Sharma VP, Geusz ME. Circadian rhythms in doxorubicin nuclear uptake and clock control of C6 glioma cells. J Cancer Ther. 2016;7(8):558-72. doi:10.4236/jct.2016.78059.

47. Fan K, Uzman BG. Rat glioma cells (C6) cultured in serum-free defined medium. Exp Cell Res. 1977;106(2):397-401.

48. Janicke RU, Sprengart ML, Wati MR, Porter AG. Caspase-3 is required for DNA fragmentation and morphological changes associated with apoptosis. J Biol Chem. 1998;273(16):9357-60.

49. Zheng TS, Schlosser SF, Dao T, Hingorani R, Crispe IN, Boyer JL, et al. Caspase-3 controls both cytoplasmic and nuclear events associated with Fas-mediated apoptosis in vivo. Proc Natl Acad Sci U S A. 1998;95(23):13618-23.

50. Hosseini A, Ghorbani A. Cancer therapy with phytochemicals: evidence from clinical studies. Avicenna J Phytomed. 2015;5(2):84-97.

51. Mohanty C, Sahoo SK. The in vitro stability and in vivo pharmacokinetics of curcumin prepared as an aqueous nanoparticulate formulation. Biomaterials. 2010;31(25):6597-611. doi:10.1016/j.biomaterials.2010.04.062.

52. Anand P, Kunnumakkara AB, Newman RA, Aggarwal BB. Bioavailability of curcumin: problems and promises. Mol Pharm. 2007;4(6):807-18.

53. Wang YJ, Pan MH, Cheng AL, Lin LI, Ho YS, Hsieh CY, et al. Stability of curcumin in buffer solutions and characterization of its degradation products. J Pharm Biomed Anal. 1997;15(12):1867-76.

54. Chignell CF, Bilski P, Reszka KJ, Motten AG, Sik RH, Dahl TA. Spectral and photochemical properties of curcumin. Photochem Photobiol. 1994;59(3):295-302.

55. Ghosh M, Ryan RO. Curcumin homing to the nucleolus: mechanism for initiation of an apoptotic program. J Nutr Biochem. 2014;25(11):1117-23. doi:10.1016/j.jnutbio.2014.06.009.

56. Jayaprakasha GK, Jagan Mohan Rao L, Sakariah KK. Improved HPLC method for the determination of curcumin, demethoxycurcumin, and bisdemethoxycurcumin. J Agric Food Chem. 2002;50(13):3668-72.

57. Sahar S, Sassone-Corsi P. The epigenetic language of circadian clocks. Handb Exp Pharmacol. 2013;217:29-44. doi:10.1007/978-3-642-25950-0_2.

58. Mut M, Amos S, Hussaini IM. PKC alpha phosphorylates cytosolic NFkappaB/p65 and PKC delta delays nuclear translocation of NF-kappaB/p65 in U1242 glioblastoma cells. Turkish Neurosurg. 2010;20(3):277-85 doi:10.5137/1019-5149.JTN.3008-10.1.

59. Blakemore LM, Boes C, Cordell R, Manson MM. Curcumin-induced mitotic arrest is characterized by spindle abnormalities, defects in chromosomal congression and DNA damage. Carcinogenesis. 2013;34(2):351-60. doi:10.1093/carcin/bgs345.

60. Vahid F, Zand H, Nosrat-Mirshekarlou E, Najafi R, Hekmatdoost A. The role dietary of bioactive compounds on the regulation of histone acetylases and deacetylases: a review. Gene. 2015;562(1):8-15. doi:10.1016/j.gene.2015.02.045

61. Lirdprapamongkol K, Sakurai H, Suzuki S, Koizumi K, Prangsaengtong O, Viriyaroj A, et al. Vanillin enhances TRAIL-induced apoptosis in cancer cells through inhibition of NF-kappaB activation. In vivo. 2010;24(4):501-6.

62. Yang ST, Huang AC, Tang NY, Liu HC, Liao CL, Ji BC et al. Bisdemethoxycurcumin-induced $S$ phase arrest through the inhibition of cyclin $\mathrm{A}$ and $\mathrm{E}$ and induction of apoptosis via endoplasmic reticulum stress and mitochondria-dependent pathways in human lung cancer $\mathrm{NCl} \mathrm{H460}$ cells. Environmental toxicology. 2015. doi:10.1002/tox.22191

63. Xu JH, Yang HP, Zhou XD, Wang HJ, Gong L, Tang CL. Autophagy Accompanied with Bisdemethoxycurcumin-induced Apoptosis in Non-small Cell Lung Cancer Cells. Biomed Environ Sci. 2015;28(2):105-15. doi:10.3967/bes2015.013.

64. Shen L, Ji HF. The pharmacology of curcumin: is it the degradation products? Trends Mol Med. 2012;18(3):138-44. doi:10.1016/j.molmed.2012.01.004.

65. Lee AY, Fan CC, Chen YA, Cheng CW, Sung YJ, Hsu CP, et al. Curcumin Inhibits Invasiveness and Epithelial-Mesenchymal Transition in Oral Squamous Cell Carcinoma Through Reducing Matrix Metalloproteinase 2, 9 and Modulating p53-E-Cadherin Pathway. Integr Cancer Ther. 2015;14(5): 484-90. doi:10.1177/1534735415588930.

66. Gordon ON, Luis PB, Ashley RE, Osheroff N, Schneider C. Oxidative Transformation of Demethoxy- and Bisdemethoxycurcumin: Products, Mechanism of Formation, and Poisoning of Human Topoisomerase llalpha. Chem Res Toxicol. 2015;28(5):989-96. doi:10.1021/acs.chemrestox.5b00009.

67. Lestari M, Indrayanto G. Curcumin. In: Harry GB, editor. Profiles of Drug Substances, Excipients, and Related Methadology. San Diego: Academic: 2014. p. 113-204. 
68. Wu JC, Tsai ML, Lai CS, Wang YJ, Ho CT, Pan MH. Chemopreventative effects of tetrahydrocurcumin on human diseases. Food Funct. 2014;5(1):12-7. doi:10.1039/c3fo60370a.

69. Luthra PM, Kumar R, Prakash A. Demethoxycurcumin induces Bcl-2 mediated G2/M arrest and apoptosis in human glioma U87 cells. Biochem Biophys Res Commun. 2009;384(4):420-5. doi:10.1016/j.bbrc.2009.04.149.

70. Grechez-Cassiau A, Rayet B, Guillaumond F, Teboul M, Delaunay F. The circadian clock component BMAL1 is a critical regulator of p21WAF1/CIP1 expression and hepatocyte proliferation. J Biol Chem. 2008;283(8):4535-42. doi:10.1074/jbc.M705576200.

71. Sotak M, Polidarova L, Ergang P, Sumova A, Pacha J. An association between clock genes and clock-controlled cell cycle genes in murine colorectal tumors. Int J Cancer. 2013;132(5):1032-41. doi:10.1002/ijc.27760.

72. Yeom M, Pendergast JS, Ohmiya Y, Yamazaki S. Circadian-independent cell mitosis in immortalized fibroblasts. Proc Natl Acad Sci U S A. 2010;107(21): 9665-70. doi:10.1073/pnas.0914078107.

73. Lim KJ, Bisht S, Bar EE, Maitra A, Eberhart CG. A polymeric nanoparticle formulation of curcumin inhibits growth, clonogenicity and stem-like fraction in malignant brain tumors. Cancer Biol Ther. 2011;11(5):464-73.

74. Vyas A, Dandawate P, Padhye S, Ahmad A, Sarkar F. Perspectives on new synthetic curcumin analogs and their potential anticancer properties. Curr Pharm Des. 2013;19(11):2047-69.

\section{Submit your next manuscript to BioMed Central} and we will help you at every step:

- We accept pre-submission inquiries

- Our selector tool helps you to find the most relevant journal

- We provide round the clock customer support

- Convenient online submission

- Thorough peer review

- Inclusion in PubMed and all major indexing services

- Maximum visibility for your research

Submit your manuscript at www.biomedcentral.com/submit 